\title{
ANÁLISE SISTÊMICA DA EXPLORAÇÃO MINERAL E O SEU CONTEXTO SÓCIO-ECONÔMICO NO MÉDIO JEQUITINHONHA, MG*
}

\author{
Sergio Túlio de Pinho-Tavares ${ }^{1}$, Cristiane Castañeda ${ }^{2} \&$ \\ Antônio Carlos Pedrosa-Soares ${ }^{2}$
}

\begin{abstract}
RESUMO
A análise sistêmica da exploração de minerais pegmatíticos, tanto de coleção, como industriais quanto os gemológicos, aponta quatro variáveis interligadas entre si. No aspecto social, as relações de trabalho no garimpo são fundamentadas na participação nos lucros de uma produção normalmente instável e que não garante renda fixa ao garimpeiro. No âmbito econômico, ressalta-se o cenário de corrupções e fraudes que envolvem a saída dos minerais gemas dos garimpos. No ponto de vista ambiental, a disposição inadequada das pilhas de rejeito que vêm acelerando o assoreamento dos cursos d'água da região. No critério políticoambiental observa-se uma população caracterizada pela pobreza uma vez que a atividade garimpeira não gera nenhum benefício para a comunidade. Uma nova postura da atividade garimpeira, propiciando a produção concomitante de minerais industriais e de minerais gemas, representa uma medida mitigatória para atenuar os problemas apontados por essas variáveis.
\end{abstract}

Palavras-chave: atividade garimpeira, minerais industriais, minerais gemas

\begin{abstract}
The systemic analysis of the exploration of pegmatitic minerals, for collections, gems or industrials, indicates four interlinked variables. In the social aspect, the diggings work relationships are usually based in the profit sharing of an unstable production and that doesn't guarantee fixed salary to the prospector. In the economical ambit, it is pointed out the scenery of corruptions and frauds that involve the exit of the gems of digging. In the environmental aspect, the inadequate dispositions of the reject piles are accelerating by the wearing down of the rivers in that area. In the politic-environmental criterion, it is observed a population characterized by the poverty because the dig ging (garimpo as Brasilian popular name) doesn't generate any benefit for the community. A new posture of the digging, providing the production of industrial minerals associated with the gem-minerals exploration represents a necessary step to lessen the exposed problems for those variables.
\end{abstract}

Keywords: digging, industrial minerals, gem-minerals

\section{INTRODUÇÃO}

O Médio Vale do Rio Jequitinhonha é uma região de grandes contrastes. Apesar de ser considerada uma das regiões mais subdesenvolvidas, tendo um dos maiores índices de pobreza do país, o subsolo da região abriga uma das maiores riquezas minerais do Brasil em minerais gemas e minerais industriais. Entretanto, a exploração inadequada desses minerais e a falta de planejamento e gerenciamento na atividade minerária, essencialmente dominada por garimpos, faz com que essa riqueza mineral não traga benefícios para a melhoria da qualidade de vida na região.

É de extrema relevância expor a influência da atividade garimpeira mal planejada e gerenciada a partir da interpretação e análise do problema, a fim de encontrar ou mesmo propor soluções que possam minimizar as diferenças sociais e a agressão ao meio ambiente, aumentar a produtividade do capital e do trabalho advindos desta atividade econômica e estimular a melhoria qualitativa na cultura exploratória dos minerais gemas.

\section{VISÃO SISTÊMICA DA PROBLEMÁTICA DA ATIVIDADE GARIMPEIRA}

Pode-se analisar a problemática da exploração inadequada de minerais gemas e a falta (ou mesmo inadequação) de planejamento da mineração como pontos-chave no desenvolvimento de um raciocínio sistêmico composto por quatro diferentes variáveis que interagem entre si.

Segundo Beni (2002) essa visão holística do todo traduz uma realidade que não pode ser desmembrada, sendo incompreensível entender uma única variável se desprezar seu contexto e seu relacionamento com outra(s) variável(is). Para tal, propor-se-á um sistema integrado entre as variáveis que compõem o contexto da atividade exploratória de minerais gemas na região do Médio Vale do Rio Jequitinhonha, conforme esquematizado na Figura 1.

Historicamente, a exploração de minerais gemas nas regiões norte e nordeste de Minas Gerais é feita a partir de garimpos. As técnicas empregadas na extração são rudimentares, realizadas por garimpeiros geralmente de

\footnotetext{
* Suporte financeiro: PROGEMAS (CTMineral, MCT), CAPES, CNPq

1. Fosfertil Fertilizantes Fosfatados S.A., sergiogeo@bol.com.br 2. CPMTC-IGC-UFMG
} 


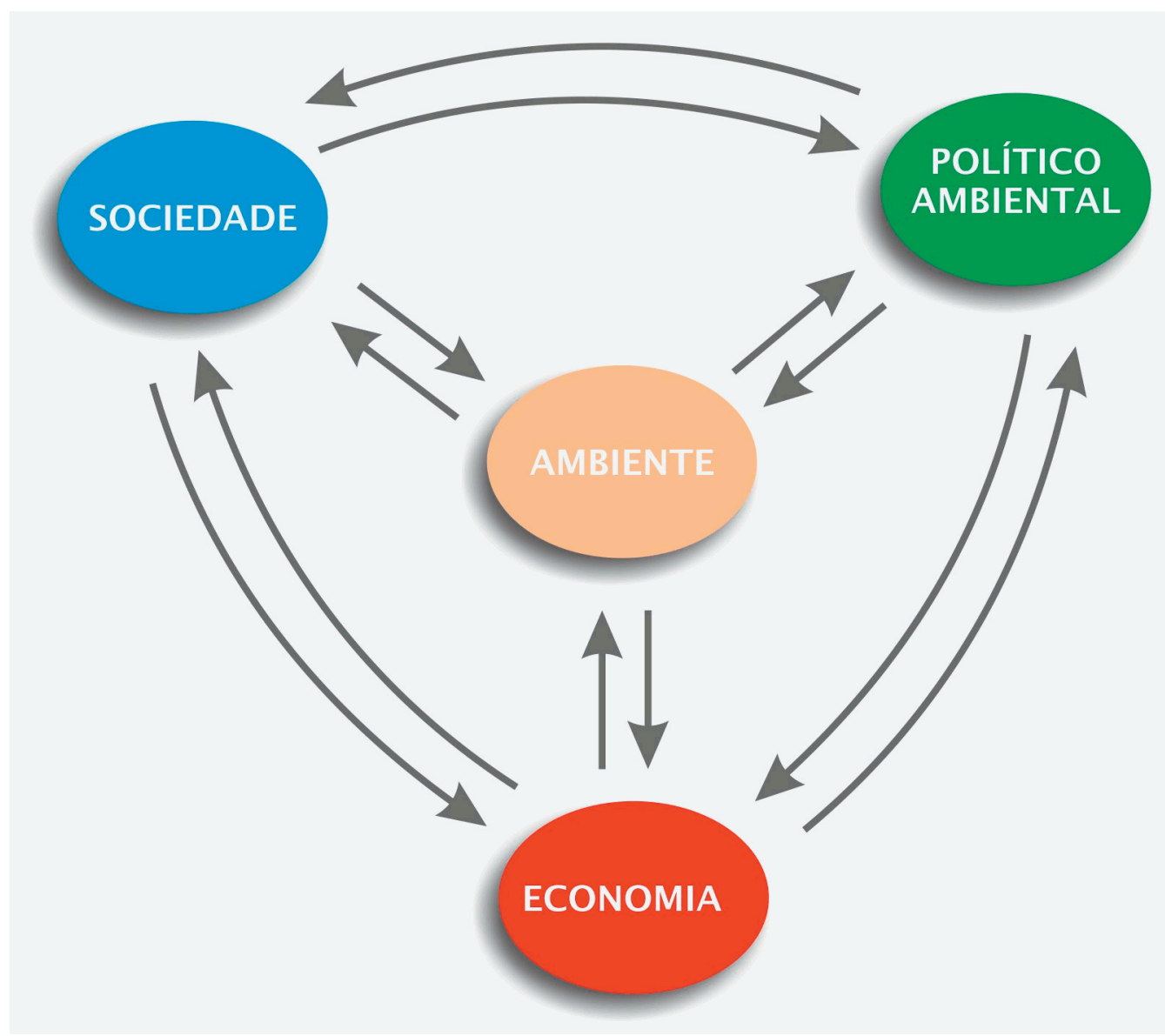

Figura 1 - Modelo proposto de visão holística das variáveis que configuram o cenário da exploração mineral no Médio Jequitinhonha, $M G$.

baixa ou nenhuma escolaridade, tornando esta atividade de grande risco. Além disso, as regiões produtoras de minerais gemas são marcadas por pobreza e violências nas comunidades.

As relações de trabalho e o modo de produção no garimpo configuram-se em três esferas principais: o dono da terra, o fornecedor e o(s) garimpeiro(s). O dono da terra é o proprietário do terreno explorado. O fornecedor é aquele que mantém o garimpo, custeando a alimentação e os equipamentos necessários à exploração. O garimpeiro é o indivíduo que vende sua força de trabalho, ou seja, é a mão-de-obra (PedrosaSoares 1985).

Normalmente, o garimpeiro não é remunerado pelo fornecedor, seja por falta de condições financeiras deste, ou seja, pelo fato do trabalhador esquivar-se do salário em troca de uma porcentagem maior na extração. Este regime de porcentagem é predominante nas relações de trabalho no garimpo (Lazarin \& Rabelo 1984).

A divisão dos lucros na atividade garimpeira é fator de conflitos e violência, pois não há legislação que a regulamente nesse aspecto. A Lei 7.805/89 - Regime de Permissão de Lavra Garimpeira -, que rege a atividade de garimpagem, não discute a questão da participação dos lucros. Na realidade, o dono da terra recebe entre 10 e $25 \%$ e o garimpeiro de 5 a $40 \%$ (dependendo do número de trabalhadores, quanto maior o número de garimpeiros menor é a porcentagem). $\mathrm{O}$ fornecedor é que fica com a grande parcela dos lucros por ser o mantenedor da atividade garimpeira. Entretanto, a inexistência da remuneração dos garimpeiros constitui um grande problema social. De maneira geral, o garimpeiro é um indivíduo que coexiste com a pobreza, sendo o fator social uma das variáveis componentes do sistema proposto.

A atividade extrativista (exploratória) não é certa e exata. A duração temporal do trabalho dos garimpeiros pode levar desde poucas horas até anos na tentativa de retirada de alguma pedra. Como não são cidadãos assalariados e dependem de sua produção para o sustento próprio necessitam, indesejavelmente, desfazer-se rapidamente das pedras extraídas.

Outro problema, que se introduz no sub-conjunto da variável econômica, é que as pedras são vendidas a preços muito baixos a intermediários, indivíduos que atuam como agiotas, que as revendem por até 10 vezes o valor em centros urbanos como Teófilo Otoni e Governador Valadares. Essas negociações quase sempre são feitas ilegalmente de forma a burlar a tributação. A figura do "curiango", que normalmente é representada por um garimpeiro, aparece nesses momentos. A “curiangagem" consiste em vender 
parte da produção paralelamente (comércio ilegal) para não ter que dividir as porcentagens de lucros com o fornecedor e o dono da terra.

Desta forma, a saída das pedras do garimpo é caracterizada por corrupções e sonegações de impostos. A atividade de exploração dos minerais gemas (pedras preciosas designadas pela indústria de jóias como preciosas ou semi-preciosas de acordo com a espécie mineral e estado de pureza e preservação do cristal) não gera nenhuma arrecadação tributária (e isso implica em receita) para o Estado e nem mesmo para o município, contribuindo para que a pobreza estenda-se por longos períodos da história local. Dois fatores interligados de causa e conseqüência, que configuram a variável político-cultural, inviabilizam não só os artifícios políticos para um plano de ação de desenvolvimento e crescimento local, como também impossibilitam a transformação da tributação em benefícios sociais como melhorias na saúde, na educação dentre outras. A desinformação do garimpeiro também o leva a desperdiçar pedras com qualidade gemológica inferior que estão sendo utilizadas em bijouterias com designer e ou levadas a tratamentos de embelezamento.

Atualmente, a produção de peças-de-coleção vem conquistando muito espaço nos garimpos. Peças-decoleção são variedades de minerais pegmatíticos com ou sem valor gemológico que exibem espécies minerais com belas feições, incrustações ou cristalizações perfeitas. As mais comuns são compostas por turmalinas, quartzo (hialino, murion, phantom etc.), cleavelandita (variedade lamelar da albita), lepidolita e herderita. A produção dessa variedade mineral tem gerado bons dividendos aos garimpeiros, pois algumas vezes determinada peça pode valer mais que o próprio mineral gema. Além disso, pode-se ter quantidade significativamente grande de determinadas peças, o que gera uma arrecadação maior. Entretanto, os mesmos problemas apresentados na extração dos minerais gemas são observados na extração e comercialização das peças-de-coleção: curiangagem, corrupções, sonegações de impostos etc.

Outro componente do sistema, a variável ambiente, em uma das suas interfaces é retratada pelas condições climáticas da região - baixa pluviosidade e altas temperaturas na maior parte do ano - que não favorecem as atividades agropecuárias, devido à notória escassez de água, deixando de ser assim, uma alternativa econômica de geração de renda para a população local. Dessa forma, o garimpo constitui a única base da economia da região.

É importante ressaltar o desperdício de bens minerais na atividade garimpeira. A extração de minerais gemas em pegmatitos produz toneladas de minerais industriais como quartzo, feldspatos potássicos, micas, albita, berilo não-gemológico, ambligonita, espodumênio etc. Esses subprodutos são literalmente descartados e amontoados indevidamente em pilhas de rejeitos, o que constitui um outro problema ambiental.

A falta de interesse do garimpeiro na extração e comercialização dos minerais industriais, também chamados de "minérios", se deve a três motivos principais:

1) Baixo valor agregado pelos minerais industriais: esses subprodutos são comercializados apenas no peso e a baixos valores. Um exemplo pode ser notificado quando se conversa com alguns garimpeiros ou mesmo com os funcionários da LUFI Mineração e Beneficiamento: a tonelada de feldspato potássico é de aproximadamente $\mathrm{R} \$ 30,00$ e o quilo do berilo industrial é R\$ 0,80 .

2) Pequena produção por garimpo: um serviço em um corpo pequeno ou executado sem o auxílio de compressores produz pequeno volume de minerais. O serviço do Joel Vieira Alves, por exemplo, que é executado manualmente por dois garimpeiros, produz mensalmente menos de 15 toneladas de feldspato potássico (o que renderia por mês R $\$ 450,00$ ). Valores desta ordem são considerados irrisórios pelo garimpeiro que julga não ser viável o tempo gasto ao empilhar e separar em pilhas minerais como quartzo e feldspatos potássicos, já que poderia estar procurando águamarinha ou turmalinas coradas que possuem valores unitários bem mais motivadores. Apenas a título de ilustração, o preço médio das turmalinas coradas em Coronel Murta é, em média, R\$ 80,00 o grama, excluindo-se minerais gemas "extras". Águas-marinhas de "meia-cor" e baixa qualidade gemológica valem pelo menos R\$30,00 o grama.

3) Ausência de mercado de compra para os minerais industriais, a citar como exemplo a inexistência de qualquer empresa ou mesmo pessoa física que se disponha a utilizar um caminhão como transporte mensal até o serviço do Joel Vieira Alves e coletar as 05 toneladas de feldspatos potássicos. Ainda existem dois agravantes: a distância de determinados "serviços" em relação às cidades e a falta de acesso viável e de qualidade. Por exemplo, o acesso ao serviço do Joel Vieira Alves é feito por uma trilha de aproximadamente $500 \mathrm{~m}$ que se inicia em um casebre às margens da rodovia BR-342 (rumo a Salinas).

Assim, um garimpo que visa retirar minerais industriais só inicia se uma empresa ou pessoa física que a explore possua previamente clientela, infra-estrutura e equipamentos necessários para escoar sua produção.

Atualmente, a única empresa que explora minerais industriais no município de Coronel Murta é a LUFI Mineração e Beneficiamento, com uma produção bruta de 4.000 a $4.500 \mathrm{t}$ (variando até para mais) por mês de feldspato potássico extraído de um único corpo pegmatítico: a Lavra de Água Santa.

Todos os outros serviços ficam em atividade durante um período, como é o caso do Serviço do Coca, às margens do Córrego Palmeiras. Esse serviço esteve em atividade somente no segundo semestre de 2002, quando o feldspato potássico extraído era vendido para a LUFI. Quando a empresa suspendeu a compra de seus minerais, alegando falta de clientela para escoamento do minério retirado nesse serviço, o garimpo foi 
desativado. Entretanto, a direção da LUFI considerava mais viável comprar feldspato potássico que extrair feldspatos. Uma produção mensal inferior a 3.000t torna inviável a Lavra de Água Santa.

$\mathrm{O}$ fato da LUFI também executar o beneficiamento das diversas qualidades de minérios constitui elemento imprescindível para manter o saldo lucrativo da empresa. O minério moído de feldspato potássico é vendido em torno de $\mathrm{R} \$ 100,00$ a tonelada.

Na situação atual, cada garimpo ou "serviço" produz um rejeito volumoso e rico em minerais industriais que são desperdiçados. Esse rejeito é inadequadamente estocado em pilhas que se situam em encostas de morros, o que constitui grande problema ambiental. Os fragmentos de minerais descem pelas encostas, destroem a vegetação e ficam depositados nos vales de drenagem. Esse processo, que tem provocado o assoreamento de rios e córregos e extinguindo as nascentes dos mesmos, culmina por acelerar o processo erosivo e agravar o estado de seca na região.

Em um local onde o problema da falta de água é histórico devido tanto a fatores climáticos quanto a degradação progressiva do meio ambiente, esse quadro impossibilita a irrigação de plantações e manutenção das pastagens como fonte de alimento para a pecuária. Todo esse processo pode ser percebido pela quase ausência da atividade agropecuária em municípios como Coronel Murta e Itinga.

\section{MEDIDAS MITIGATÓRIAS}

Essa situação histórica de pobreza e subdesenvolvimento observada em uma região provida de uma das maiores riquezas minerais do Brasil culminou pela necessidade de criação do PROGEMAS, um projeto de pesquisa para a explotação de corpos pegmatíticos portadores de minerais gemas das regiões de Conselheiro Pena e Araçuaí - designadas de "áreasalvo" - sob uma abordagem inovadora. O PROGEMAS tem como objetivo a inserção de tecnologia na mineração desse tipo de rocha, visando potencializar a produção de minerais gemas e demais bens minerais associados a estas. Do ponto de vista da inovação, o projeto contempla a integração de todas as fases da mineração (geologia, lavra e beneficiamento) e a visão sistêmica do corpo mineral.

O referido projeto é fruto de uma parceria das universidades UFMG, UFOP e UFRJ e dos centros de pesquisa CETEC-MG e CETEM com os órgãos federais ligados à ciência como Ministério de Ciência e Tecnologia (MTC), CTMineral, CAPES e CNPq, além do envolvimento do setor produtivo, como AJOMIG (Associação dos Joalheiros do Estado de Minas Gerais).

O PROGEMAS visa proporcionar contribuições no contexto científico-tecnológico e no aspecto econômico e social das áreas-alvo. No âmbito científico-tecnológico pretende-se: (1) elevar o conhecimento científico sobre os corpos pegmatíticos, de forma a aumentar e regularizar a produção de minerais gemas e de minerais industriais; (2) minimizar os impactos ambientais e; (3) propor novas metodologias de lavra especialmente adaptadas às peculiaridades dos pegmatitos, que visem a produção de minerais industriais, bem como adequar os processos de desmonte de rocha possibilitando a preservação dos minerais gemas.

Os setores econômicos e sociais podem apresentar melhorias quando a exploração dos pegmatitos deixar de ser organizadas nos moldes do garimpo e tornar-se uma atividade de mineração propriamente dita. Isso permitiria: (1) o desenvolvimento de indústrias para absorver a matéria-prima produzida com qualidade e regularidade; (2) a melhoria na escolaridade dos seus fucionários por própria exigência da atividade mineraria; (3) diminuir os riscos da prospecção e aumentar a segurança do trabalhador (garimpeiro) e; (4) fixar o homem na comunidade local, seja para trabalhar diretamente na mineração ou no segmento industrial, seja para trabalhar no setor de serviços.

Partindo dessas proposições, a atividade garimpeira deve assumir uma nova postura e investir na produção de minerais industriais. Esse procedimento não alteraria as relações de trabalho no garimpo. Não seriam extintas as figuras do fornecedor ou do próprio garimpeiro. Tampouco mudaria a essência e a razão histórica do garimpo. O garimpo pode e deve continuar a ser uma atividade econômica em busca de riqueza a partir da exploração de minerais gemas. Entretanto, o que mudaria seria a forma de valorização dos minerais industriais ("minérios"). Simultaneamente à exploração de minerais gemas, o garimpeiro deveria separar adequadamente em pilhas quartzo, feldspato, muscovita etc.

Os referidos minérios, mesmo que em pequenas quantidades, podem gerar uma renda mensal que mantenha o garimpo ou o próprio garimpeiro. Podese criar uma situação como forma de exemplificar essa possibilidade: com a venda mensal dos minerais industriais (10t de quartzo, 15t de feldspatos potássicos, $20 \mathrm{~kg}$ de berilo industrial) do Serviço do Joel Vieira Alves, este consegue custear a alimentação, o aluguel de um pequeno gerador e um salário de R $\$ 250,00$ por mês para cada um de seus três garimpeiros.

Dessa forma, o problema do volume de minerais seria minimizado, pois todos os garimpos estariam "estocando" sua produção de minérios.

As prefeituras municipais e empresas como a LUFI poderiam executar com uma freqüência quinzenal ou mensal esta "coleta seletiva" nos garimpos. Assim, poderia destinar determinados dias da semana para carregamento de quartzo, e depois feldspatos, muscovita, berilo etc. Seria um esquema semelhante ao da cooperativa de laticínios: o caminhão passa na fazenda (garimpo) e compra o leite produzido (mineral industrial retirado). A prefeitura ou a empresa revenderia a produção mineral garimpeira para as indústrias correspondentes.

Essa comercialização de minerais industriais tendo 
como "intermediário" o setor privado ou o poder público obviamente seria alvo de tributação e impostos. Desta maneira, a atividade mineraria garimpeira passaria a gerar recursos para a região. Os índices de pobreza diminuiriam consideravelmente com o aumento da receita municipal, refletindo na melhoria da qualidade de vida da população.

Outro benefício da comercialização de minerais industriais seria refletido no comércio de minerais gemas. Na medida em que o garimpeiro não precisa vender rapidamente seus minerais gemas - pois os minerais industriais de seu serviço lhe garantem algum retorno financeiro - , ele mesmo poderia especular e valorizar o preço do seu produto uma vez que seu estoque será maior.

Estaria sendo criada uma oportunidade de organização de um evento nesse ramo, como é a Feira de Gemas em Teófilo Otoni, também em locais como Araçuaí. Isso propiciaria ao garimpeiro e comerciantes envolvidos a oportunidade de mostrar a sua produção, valorizar o seu produto e especular um preço mais alto (e justo) para o mesmo.

A venda de minerais industriais traria também benefícios ao meio ambiente a partir do momento em que o volume das pilhas de rejeitos seria significativamente reduzido com a ausência desses minerais. Obviamente que ainda há o problema da má-disposição dessas pilhas, situadas em encostas de morros. Porém, a simples redução da quantidade de materiais do rejeito já constitui um passo importante para atenuar o problema do assoreamento das drenagens.

Ressalta-se que a eliminação do assoreamento como um dano ambiental causado pela atividade garimpeira não vai solucionar o problema dos córregos e riachos da região. A escassez de água, conforme relatada anteriormente, é causada por um somatório de fatores, tendo como principal causa a baixa pluviosidade regional.

\section{CONSIDERAÇÕES FINAIS}

O desenvolvimento de uma teoria sistêmica de análise para uma determinada problemática, como é o caso proposto por este artigo, possibilita o despertar consciente como desencadeador de uma ação coletiva dos agentes que pertencem ao ramo empresarial e a toda a comunidade envolvida no processo, criando suportes para uma atividade garimpeira bem articulada e planejada que visa promover melhorias na qualidade de vida na região, bem como outras melhorias no âmbito político, ambiental e econômico.

\section{AGRADECIMENTOS}

Os autores agradecem o suporte financeiro dos seguintes projetos: (1) "Exploração de Pegmatitos Portadores de Gemas: Uma Abordagem Inovadora", coordenado pela Profa. Maria José Gazzi Salum (Escola de Engenharia-UFMG) e financiado pelo CTMineral/ CNPq; (2) "PROGEMAS MG", coordenado pela Profa. Maria José Gazzi Salum (Escola de Engenharia-UFMG) e financiado pelo Fundo Verde Amarelo do CTMineral/ FINEP; e (3) "Evolução e Recursos Minerais do Orógeno Araçuaí", coordenado pelo Prof. Antônio Carlos Pedrosa-Soares (CPMTC-IGC-UFMG) e financiado pelo CNPq. Além destes projetos, à CAPES, pela concessão de bolsa de mestrado ao primeiro autor, dissertação aprovada em julho de 2004. Também deve ser mencionado o apoio fornecido pela empresa LUFI Mineração e Beneficiamento Ltda., desde a hospitalidade com a qual nos recebeu em Coronel Murta até ao suporte laboratorial nas análises dos minérios feldspáticos para a elaboração da mencionada dissertação de mestrado.

\section{REFERÊNCIAS BIBLIOGRÁFICAS}

Beni, M. C. Análise Estrutural do Turismo. 7. ed. São Paulo: Editora Senac, 2002, p.17-18.

Lazarin, M. A. C.; Rabelo, F. C. Garimpeiros no Nordeste de Goiás. In: Figueiredo, B. R. et al. Em busca do ouro: Garimpos e Garimpeiros no Brasil. Rio de Janeiro: Ed. Marco Zero/ CONAGE, 1984. p. 107-120.

Pedrosa-Soares, A. C. Notas sobre as relações de trabalho na garimpagem de pegmatitos do Médio Jequitinhonha - MG. In: SIMPÓSIO DE GEOLOGIA DE MINAS GERAIS, 3., 1985, Belo Horizonte. Anais... Belo Horizonte: Sociedade Brasileira de Geologia - MG, 1985. p. 332-336. 